\title{
Attitude to the study of chemistry and its relationship with achievement in an introductory undergraduate course
}

\author{
Stephen J. Brown ${ }^{1}$, Sue White ${ }^{2}$, Bibhya Sharma ${ }^{3}$, Lara Wakeling ${ }^{4}$, Mani Naiker ${ }^{5}$, Shaneel \\ Chandra $^{6}$, Romila Gopalan ${ }^{7}$, \& Veena Bilimoria ${ }^{8}$
}

\begin{abstract}
A positive attitude to a subject may be congruent with higher achievement; however, limited evidence supports this for students in undergraduate chemistry - this may result from difficulties in quantifying attitude. Therefore, in this study, the Attitude to the Study of Chemistry Inventory (ASCI) a validated instrument to quantify attitude, was used to measure attitude to chemistry in 125 undergraduates studying an introductory course in chemistry, as part of a BSc Chemistry major. The 13 week course contained 4 summative assessments: practical (PRAC), tutorial (TUT), on-line web-based learning $(O W L)$, and a final exam (FE). Sub-scales within ASCI which quantify the 'affective' and 'cognitive' components of attitude were determined. Firstly, for all 125 students, weak correlations ( $r$ ) between the affective scale score and FE $(r=0.275, P<0.01)$ and TOTAL $(r=0.228, P<0.05)$, were recorded. Secondly, $a$ low achieving (LA, $n=48)$ and a high achieving (HA, $n=77)$ group were identified using a cluster analysis procedure. The HA group scored higher than the LA group in PRAC, OWL, FE and TOTAL (all P<0.001), but the clusters were not different in their scores for either the affective or the cognitive components of attitude. There was no correlation between attitude and achievement in the HA group, and only one weak positive correlation (0.409), between the affective score and achievement in the LA group. We suggest that although a positive attitude may be an important part of the undergraduate experience, it is at best only weakly associated with achievement in undergraduate chemistry.
\end{abstract}

Keywords: attitude, chemistry education research, testing and assessment, achievement.

\section{Introduction}

A positive attitude may be congruent with higher achievement at university (Osborne, Simon, \& Collins, 2003; Xu \& Lewis, 2011; Xu, Southam, \& Lewis, 2012), however, there is a paucity of data pertaining to the importance of attitude in undergraduates majoring in chemistry

\footnotetext{
${ }^{1}$ Auckland University of Technology, Auckland, NZ, stbrown@aur.ac.nz

${ }^{2}$ Auckland University of Technology, Auckland, NZ, suwhite@aut.ac.nz

${ }^{3}$ School of Biological and Chemical Sciences, Faculty of Science, Technology and Environment, University of the South Pacific, Laucala Campus, Suva, Fiji, bibhya.sharma@usp.ac.fj

${ }^{4}$ Federation University, Mount Helen, VIC, 3350, Australia, L.wakeling@feduni.edu.au

${ }^{5}$ Federation University, Mount Helen, VIC, 3350, Australia, m.naiker@feduni.edu.au

${ }^{6}$ School of Biological and Chemical Sciences, Faculty of Science, Technology and Environment, University of the South Pacific, Laucala Campus, Suva, Fiji, shaneel.chandra@usp.ac.fj

${ }^{7}$ School of Biological and Chemical Sciences, Faculty of Science, Technology and Environment, University of the South Pacific, Laucala Campus, Suva, Fiji, romila.devi@usp.ac.fj

${ }^{8}$ School of Biological and Chemical Sciences, Faculty of Science, Technology and Environment, University of the South Pacific, Laucala Campus, Suva, Fiji, veena.bilimoria@usp.ac.fj
} 
(Bauer, 2008; Xu \& Lewis, 2011). Developing a positive attitude towards a subject may be an important component of the undergraduate experience, and as educators, we may encourage students to have a positive attitude, yet the concept of an attitude towards the study of chemistry is somewhat vague. It has been proposed (Bagozzi \& Burnkrant, 1979) that attitude could be viewed as a two-component construct, comprised of cognitive and affective components. As such, attitude has been described as a tendency to respond to a certain stimulus, for example, the study of chemistry, where the response has both a cognitive (what do I think about studying chemistry?) and an affective (how do I feel about studying chemistry?) dimension (Rosenberg \& Hovland, 1960). Affective reflects emotional responses through individual preferences to the stimulus, whereas the cognitive reflects an individual's beliefs and knowledge about the stimulus (Xu, Southam, \& Lewis, 2012).

A students' attitude is of concern to the educator as it may influence the students' engagement with course material, connectedness with peers (and the institution), and possibly, academic achievement and progression through an undergraduate programme (Handelsman et al., 2005; Miller et al., 1996). To assess the influence of attitude on the study of chemistry in an undergraduate curriculum, appropriate and valid instruments to quantify attitude, and the components of attitude, have been developed. For example, the Chemistry Expectations Survey CHEMX (Grove \& Bretz, 2007), Chemistry Attitudes and Experiences Questionnaire - CAEQ (Coll, Dalgety, \& Salter, 2002), and the Colorado Learning Attitudes about Science Survey CLASS (Barbera et al., 2008; Heredia \& Lewis, 2012) are tools that have been used to quantify attitude to the study of chemistry in undergraduate students. Also, the Attitude to the Study of Chemistry Inventory - ASCI (Bauer, 2008; Xu \& Lewis, 2011; Brown et al., 2014), and the shortened version - ASCIv2 (Xu, Southam, \& Lewis, 2012; Brandriet et al., 2011) may also be suitable tools to quantify attitudes to chemistry in undergraduate students. In previous studies which used exploratory factor analysis, and subsequent confirmatory factor analysis, both ASCI and ASCIv2 have consistently been shown to contain two sub-scales congruent with the affective and cognitive components of attitude.

Although there is a complex relation between attitude and achievement (Freedman, 1997; Steiner \& Sullivan, 1984), the limited previous work on chemistry majoring students has suggested that associations between both the cognitive and affective components of attitude, and academic performance were weak (Bauer, 2008). For example, a correlation of 0.39 between 'Intellectual Accessibility (cognitive)' and course grade has been reported (Bauer, 2008), while others (Xu \& Lewis, 2011) reported correlations between achievement and both cognitive and affective components of attitude as 0.30 and 0.34 , respectively. Although significant correlations between achievement and attitude were reported in students majoring in chemistry at university (Brandriet et al., 2011), the strength of these associations was poor. These weak correlations between attitude and achievement may suggest that attitude is independent of, or at best, only weakly associated with achievement in an undergraduate course in chemistry.

Therefore, the aims of the current study were firstly, to investigate the relation between attitude and achievement in chemistry majoring students studying a first year course in introductory chemistry, and secondly, to investigate the relation between attitude and achievement in those students identified as low achieving and high achieving within the same group. We hypothesised that weak associations between attitude and achievement would prevail in the full sample, but there would be stronger associations in a sub-group of higher achievers. 


\section{Methods}

This study received approval from the host institution Ethics Committee, a requirement of which was to obtain written permission of each participating student to access their grades and assessment scores. Students' marks for each assessed component were entered into a spreadsheet alongside their responses to the Attitude to the Study of Chemistry Inventory (ASCI). For a full description of this instrument, see Bauer (2008). This instrument, in paper format, was distributed to students by an impartial observer during routine class times. Students were required to identify their completed ASCI by their student number - a unique identifier for that student and specific to the host institution, prior to collection by the same observer.

The ASCI was administered in week 7 of the 13 week course. This time point was chosen as it has an advantage of including students who are late in their course enrolment, but avoids those students who enrol on-time, yet switch to other courses in the first few weeks of the semester. We also assumed that by week 7 of the course, students were relatively settled in their work habits and were engaging with the material consistent with tutor expectations. Quantifying attitude mid-way through the course may also avoid capturing negative emotions which could be induced by a fear of final examinations.

Assessed components in the chemistry course were practical (PRAC), on-line web learning (OWL), tutorial (TUT), and final exam (FE) - collectively these contributed to the total mark for the course (TOTAL). The course contained theoretical and experiential learning, with supporting material provided in lecture, tutorial, and practical settings consistent with a modern, large scale publicly funded university. Throughout the 13 week course, students were given marking rubrics for assessed work, and feedback on assessed components (with the exception of the final exam) within two weeks of submission.

\section{Data analysis}

On completed ASCI forms, scale reversal was carried out on ASCI items 1, 3, 6, 7, 9, 11, $12,14,15$, and 18, thus allowing all 'negative' terms to be chosen with 1 as the response, and all 'positive' terms to be chosen with a 7 response. Four items constituted the cognitive sub-scale: these were 1, 4, 5, and 10. Items which constituted the affective sub-scale were 7, 11, 14, and 17. For each respondent, scores for the items on each sub-scale were summed, thus giving a single value for that scale (maximum score $=28$ ). The relation between the scores for affective and cognitive sub-scales, and assessed components, was determined for all respondents $(n=125)$ using the Pearson correlation coefficient. A twostep cluster analysis was used to identify if groupings existed within the data (Kaufman \& Rousseeuw, 2005) - this is an exploratory tool designed to reveal natural groupings (or clusters) within a data set that would otherwise not be apparent. When clusters were identified, further correlations between attitude and achievement were carried out, with data from each cluster. All statistical procedures were carried out using appropriate software (IBM SPSS Statistics 19).

\section{Results}

There were 125 complete sets of data, each comprising a mark for all assessed components and completed ASCI. Students not returning a mark for any assessed component and students which received credit for prior learning were excluded from the analysis. The relations 
Brown, S.J., White, S., Sharma, B., Wakeling, L., Naiker, M., Chandra, S., Gopalan, R., \& Bilimoria, V.

between the assessment scores and components of attitude were explored using Pearson correlation, and this was done for the entire group, and the separate clusters (data shown in table $1)$.

Table1

Attitude versus achievement in undergraduate chemistry majoring students. Data shown are the Pearson correlation coefficients for the entire cohort $(n=125)$, and the Low Achieving $(n=48)$ and High Achieving $(\mathrm{n}=77)$ clusters.

\begin{tabular}{|l|l|l|l|l|l|l|}
\cline { 3 - 7 } \multicolumn{2}{c|}{} & TUT & PRAC & OWL & FE & TOTAL \\
\hline \multirow{2}{*}{$\begin{array}{l}\text { All students } \\
\text { Low Ach })\end{array}$} & cognitive & -.046 & -.017 & .150 & .160 & .170 \\
\cline { 2 - 7 }$(\mathrm{n}=48)$ & affective & -.162 & -.073 & .128 & $.275^{* *}$ & $.228^{*}$ \\
\hline \multirow{2}{*}{$\begin{array}{l}\text { High Achieving } \\
(\mathrm{n}=77)\end{array}$} & cognitive & -.126 & -.057 & -.054 & .187 & .087 \\
\cline { 2 - 7 } & affective & -.245 & -.182 & -.152 & $.409^{* *}$ & .162 \\
\cline { 2 - 7 } & affective & -.104 & -.184 & .162 & .152 & .176 \\
\hline
\end{tabular}

$* \mathrm{P}<0.05, * * \mathrm{P}<0.01$

The two-step cluster analysis identified two clusters (see figure 1), which have been described as low achieving (LA, $n=48$ ) and high achieving (HA, n=77), with a cluster ratio of 1.6.

\section{Table 2}

Mean (SD) values for each variable in the entire group, and the two clusters. Values were compared between the clusters using unpaired Student t-tests. Key: practical (PRAC), on-line web based learning (OWL), tutorial (TUT), final exam (FE), total mark (TOTAL).

\begin{tabular}{|l|l|l|l|l|l|l|}
\hline & \multicolumn{2}{|l|}{ entire cohort $(\mathrm{n}=125)$} & \multicolumn{2}{l|}{ Low Achieving $(\mathrm{n}=48)$} & \multicolumn{2}{l|}{ High Achieving (n=77) } \\
\hline & mean & SD & mean & SD & mean & SD \\
\hline TUT & 80.9 & 12.1 & 81.3 & 12.6 & 80.7 & 11.8 \\
\hline PRAC & 92.1 & 12.4 & $84.9^{*}$ & 15.5 & 96.7 & 6.8 \\
\hline OWL & 27.9 & 6.9 & $21.4^{*}$ & 5.6 & 31.9 & 3.8 \\
\hline FE & 24.5 & 8.8 & $16.0^{*}$ & 5.2 & 29.7 & 6.1 \\
\hline TOTAL & 52.4 & 14.6 & $37.4^{*}$ & 8.4 & 61.7 & 8.6 \\
\hline Cognitive & 13.8 & 3.9 & 13.0 & 3.6 & 14.3 & 4.0 \\
\hline Affective & 20.0 & 3.8 & 19.3 & 3.7 & 20.5 & 3.8 \\
\hline
\end{tabular}

$* \mathrm{P}<0.001$ 


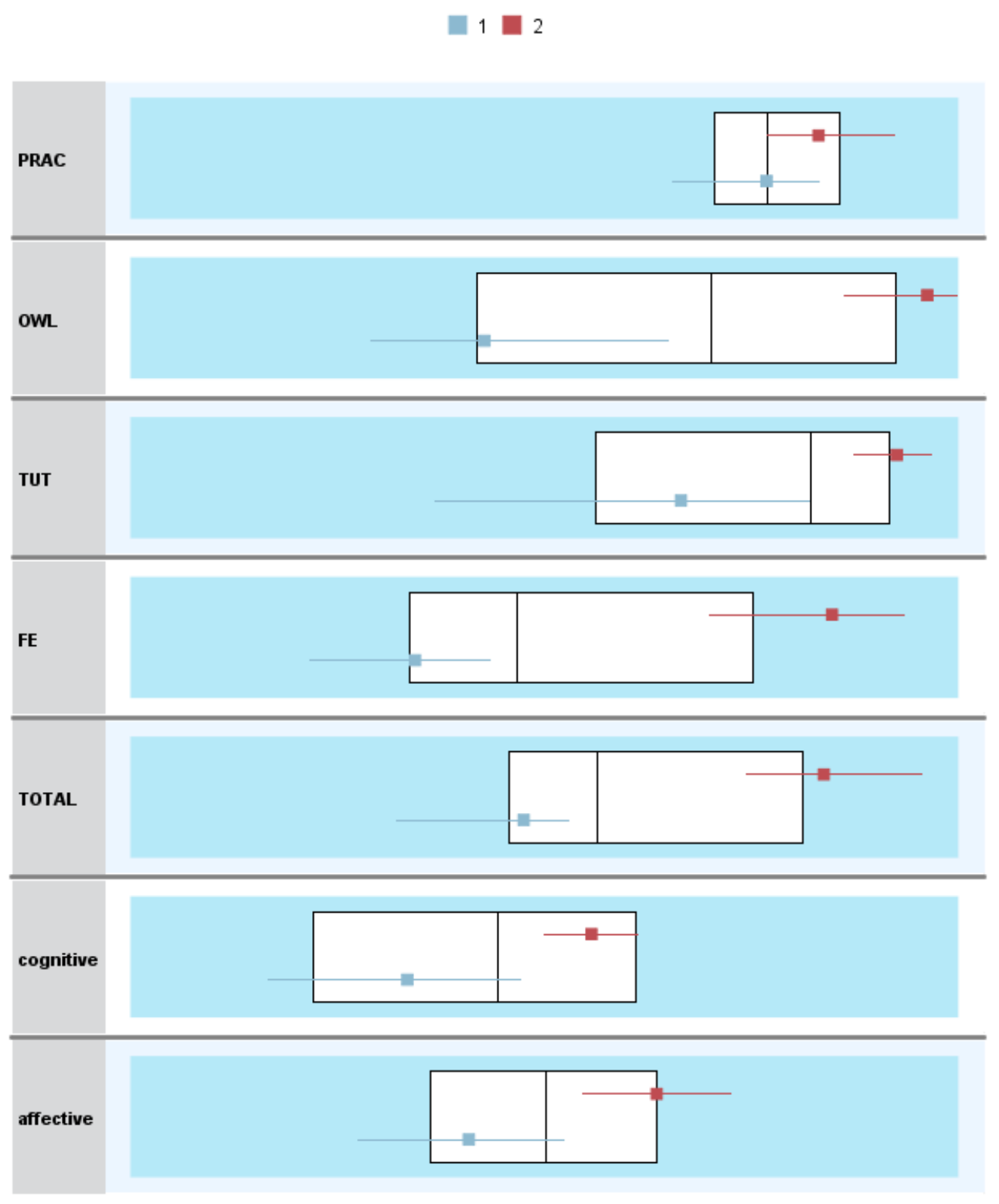

Figure 1. Cluster analysis of student achievement and attitude in undergraduate first year chemistry. For each input variable, the open white box indicates the range between the upper and lower quartile, with the central line indicating the median value. Two clusters were identified: a low achieving group (1, solid blue square with blue whiskers) and a high achieving group (2, solid red square with red whiskers). Inputs are normalised $(0-100 \%)$ and include practical (PRAC), on-line web based learning (OWL), tutorial (TUT), final exam (FE), total mark (TOTAL), and cognitive and affective components of attitude.

When the two clusters were compared in terms of their assessment scores, the HA cluster scored significantly higher in the assessed components: PRAC, OWL, FE, and TOTAL (see table 2).

When the scores for both cognitive and affective components of attitude were compared between the low achieving and the high achieving cluster, there was no significant difference 
between clusters. Thus, although membership of a cluster could be predicted from most of the achievement scores (with the exception of tutorial score), components of attitude had little or no effect on determining cluster membership.

\section{Discussion}

In this study, we were interested in the relation between attitude and achievement in a sample of university students studying introductory chemistry as part of a BSc chemistry major. The questionnaire we used to quantify attitude contained two sub-scales - these quantified the affective component and the cognitive component of attitude. We also used five summative assessment scores to represent a student's achievement on the course. Our study uniquely reports a twostep cluster analysis which identified a low achieving and a high achieving cluster, and for both clusters, components of attitude (both cognitive and affective) were not different. A further unique finding was that the two clusters could be distinguished by the majority of the achievement scores, but not by the attitude scores. Also, when the initial group was separated into the high achieving and low achieving clusters, the only significant positive correlation was between the affective score and achievement in the final exam in the low achieving group. Thus, the findings of our study suggest that there was no clear association between achievement and attitude in undergraduates studying chemistry - a finding consistent with previous reports (Bauer, 2008; Brandriet et al., 2011; Xu \& Lewis, 2011) on similar student groups.

The first aim of this study was to investigate the relation between attitude and achievement in undergraduate students undertaking an introductory course in chemistry. This aim was dependent on the efficacy and validity of the instrument we chose to quantify attitude. The ASCI has been shown to be a valid instrument to quantify attitude, with an internal structure consistent with the affective and cognitive components of attitude, and thus fitting with the theoretical composition of attitude. Exploratory factor analysis of the data obtained using ASCI (Bauer, 2008) initially indicated latent factors which included intellectual accessibility (concordant with 'cognitive'), emotional satisfaction and anxiety (concordant with 'affective'). Further studies (Brown et al., 2014; Xu \& Lewis, 2011; Xu, Villafane, \& Lewis, 2013) have confirmed this internal data structure, by consistently showing that both affective and cognitive sub-scales are contained within ASCI. Thus, we are confident that the instrument used to quantify attitude was appropriate and valid for this group of students.

Higher scores obtained for the affective and cognitive sub-scales may indicate a more positive attitude to chemistry. However, the weak correlation between attitude and achievement in this study suggested that a student's achievement in this introductory chemistry course was independent of the student's attitude. It is unlikely that an instrument purporting to measure attitude would exhibit a very strong correlation with achievement, as this would suggest the instrument is simply another measure of content knowledge. We suggest that it was unlikely that students on this course were ambivalent in their attitude to the study of chemistry, as all students had chosen to study a named BSc major in chemistry. However, the motivation behind the choice to study chemistry was not investigated in this study, and thus it may be possible that external factors (for example, parental and/or financial pressures) strongly influenced subject choice at university. Although speculative, we suggest that external factors which influence subject choice at university may impact attitude to that choice without affecting achievement on an introductory course. The lack of a strong, positive correlation between measures of attitude and achievement in undergraduate chemistry is consistent with previous research, although few 
studies which report a change in attitude among students indicate the effect of this change on achievement (Berg, 2005). We suggest that further analysis of the possible relation between attitude and achievement in undergraduates studying a chemistry major should identify those students in which a change in attitude has been identified.

Although ASCI did not require content knowledge in chemistry, it assumes a familiarity with the terms used for each item, and a misunderstanding of the terms may lead to error. In the current study, all participants were studying in the English language, however, the cultureinclusive curriculum and diversity of a modern, large publicly funded university pre-disposes the student cohort to be multi-lingual (Brown et al., 2014). Thus, it is possible that participants in this study assigned different meanings to some of the terms used in the ASCI, and this may restrict the use of a semantic differential instrument in such a multi-lingual population. The ASCI was administered in week 7, however, this timing was subjective and may have influenced our measurement of attitude. It is likely that a student's attitude will change as they progress through a course, and be influenced by events such as examinations and test scores. Further research is required to determine the consistency of attitude scores (both cognitive and affective) obtained using the ASCI instrument throughout a course with multiple and varied assessment points. For example, the short term influence of an examination on attitude may be of interest as it is likely that success (or failure) in a summative assessment will influence attitude. Alternatively, the consistency and robustness of attitude may ensure that measures obtained using ASCI are unaffected by short term influences during the 13 week course.

Our second aim was to investigate relations between attitude and achievement in groups of high achieving and low achieving students. In the current study, identifying two clusters with the cluster analysis enabled us to determine a low achieving and a high achieving group, and this represents a unique approach to the study of attitude and achievement in undergraduate chemistry. These clusters could be separated by achievement scores, but not by attitude scores, thus suggesting that attitude (both the cognitive component and the affective component) was similar regardless of cluster. There were consistently low correlations between measures of achievement and attitude in both clusters, and therefore we reject the statement "... there would be stronger associations in a sub-group of high achievers" which formed part of our hypothesis. Thus, although having (or developing) a positive attitude to study may be an important part of the undergraduate experience, there is little evidence to support any strong relations between attitude and achievement in this introductory chemistry course.

In the current study, we chose to adopt a cluster analysis approach to identify groupings within our data - membership of the group was determined by scores on assessment tasks and the attitude subscale scores. Although both cluster analysis and discriminant analysis classify objects into categories, discriminant analysis requires prior knowledge of group membership (and therefore unsuitable in this study). In contrast, the goal of our cluster analysis was to identify the actual groups. Using the two-step cluster analysis technique, the number, size, and membership of a group is unknown at the outset. In the procedure, the first step assigns individuals to pre-clusters, and in the second step, these pre-clusters are grouped using a hierarchical clustering algorithm - this algorithm determines how many clusters are formed (Kaufman \& Rousseeuw, 2005). In our study, the low and high achieving groups identified by the two-step cluster analysis could be distinguished by all achievement scores, however, it was possible that a student may be 'borderline' between clusters. The risk of allocating an individual to the wrong group is reduced by using all achievement scores ( 5 inputs) and both attitude subscale scores in the analysis. In future studies, we may adopt an a priori grouping, for example,

Journal of the Scholarship of Teaching and Learning, Vol. 15, No. 2, April 2015. 
based on the previous year's attainment in all chemistry related subjects or on university entrance exam performance to study the influence of novel pedagogies designed to improve attitude in distinct groups.

In conclusion, this study has indicated that measures of attitude and the components of attitude (affective and cognitive), were independent of achievement in undergraduates majoring in chemistry. This independence was evident in both low and high achievers, when these groups were formed using a twostep cluster analysis. We suggest that further research into the possible relationships between attitude and achievement in undergraduate studies of chemistry include evidence of underlying motivators for this subject choice.

\section{References}

Gosser, D. K., \& Roth, V. (1998). The workshop chemistry project: Peer-led team learning. Journal of Chemical Education, 75, 185-187. doi:10.1021/ed075p185.

Bagozzi, R.P., \& Burnkrant, R.E. (1979). Attitude measurement and behaviour change: a reconsideration of attitude organization and its relationship to behaviour. Advances in Consumer Research, 6, 295-302. doi: 10.1108/13612021011046101

Barbera, J., Adams, W.K., Wieman, C.E., \& Perkins, K.K. (2008). Modifying and validating the Colorado Learning Attitudes about Science Survey for use in chemistry. Journal of Chemical Education, 85(10), 1435-1439. doi: 10.1021/ed085p1435

Bauer, C.F. (2008). Attitude towards chemistry: A semantic differential instrument for assessing curriculum impacts. Journal of Chemical Education, 85(10), 1440-1445. doi:

10.1021/ed085p1440

Berg, C. (2005). Factors relating to observed attitude change toward learning chemistry among university students. Chemistry Education Research and Practice, 6(1), 1-18. doi:

$10.1039 / \mathrm{b} 4 \mathrm{rp} 90001 \mathrm{~d}$

Brandriet, A.R., Xu, X., Bretz, S.L., \& Lewis, J.E. (2011). Diagnosing changes in attitude in first-year college chemistry students with a shortened version of Bauer's semantic differential. Chemistry Education Research and Practice, 2011, 12, 271-278.

Brown, S.J., Sharma, B.N., Wakeling, L., Naiker, M., Chandra, S., Gopalan, R.D., \& Bilimoria, V.B. (2014). Quantifying attitude to chemistry in students at the University of the South Pacific. Chemistry Education Research and Practice, 15, 184-191. doi: 10.1039/c3rp00155e

Coll, R.K., Dalgety, J., \& Salter, D. (2002). The development of the chemistry attitudes and experiences questionnaire (CAEQ). Chemistry Education Research and Practice in Europe, 3(1), 19-32. doi: 10.1039/b1rp90038b

Freedman, M.P. (1997). Relationships among laboratory instruction, attitude toward science, and achievement in science knowledge. Journal of Research in Science Teaching, 34(4), 343-357. doi: 10.1002/(SICI)1098-2736(199704)34:4<343::AID-TEA5>3.0.CO;2-R 
Brown, S.J., White, S., Sharma, B., Wakeling, L., Naiker, M., Chandra, S., Gopalan, R., \& Bilimoria, V.

Grove, N.P, \& Bretz S.L. (2007). CHEMX: Assessing students' cognitive expectations in learning chemistry. Journal of Chemical Education, 84(9), 1416-1424. doi: 10.1021/ed084p1524

Handelsman, M.M., Briggs, W.L., Sullivan, N., \& Towler, A. (2005). A measure of college student course engagement. The Journal of Educational Research, 98(3), 184-191. doi: 10.3200/JOER.98.3.184-192

Heredia, K., \& Lewis, J.E. (2012) A psychometric evaluation of the Colorado Learning Attitudes about Science Survey (CLASS) for use in chemistry. Journal of Chemical Education, 89(4), 436-441. doi: 10.1021/ed100590t

Kaufman, L., \& Rousseeuw, P.J. (2005). Finding groups in data: An introduction to cluster analysis. Wiley, Hoboken, NY.

Lovelace, M., \& Brickman, P. (2013). Best practices for measuring students' attitudes toward learning science. CBE - Life Sciences Education, 12, 606-617. doi: 10.1187/cbe.12-11-0197

Miller, R.B., Greene, B.A., Montalvo, G.P., Ravindran, B., \& Nichols, J.D. (1996). Engagement in academic work: The role of learning goals, future consequences, pleasing others, and perceived ability. Contemporary Educational Psychology, 21, 388-422. doi: 10.1006/ceps.1996.0028

Osborne, J., Simon, S., \& Collins, S. (2003). Attitudes towards science: A review of the literature and its implications. International Journal of Science Education, 25(9), 1049-1079. doi: $10.1080 / 0950069032000032199$

Rosenberg, M.J., \& Hovland, C.I. (1960). Cognitive, affective and behavioural components of attitudes. In M.J. Rosenberg \& C.I. Hovland (Eds.) Attitude organization and change: An analysis of consistency among attitude components. New Haven: Yale University Press, USA.

Steiner, R., \& Sullivan, J. (1984). Variables correlating with student success in organic chemistry. Journal of Chemical Education, 61, 1072-1074. doi: 10.1021/ed061p1072

Xu, X., \& Lewis, J.E. (2011). Refinement of a chemistry attitude measure for college students. Journal of Chemical Education, 88, 561-568. doi: 10.1021/ed900071q

Xu, X., Southam, D., \& Lewis, J.E. (2012). Attitude toward the subject of chemistry in Australia: An ALIUS and POGIL collaboration to promote cross-national comparisons. Australian Journal of Education in Chemistry, 72, 32-36.

Xu, X., Villafane, S.M., \& Lewis, J.E. (2013). College students' attitudes toward chemistry, conceptual knowledge and achievement: structural equation model analysis. Chemistry Education Research and Practice, 14, 188-200. doi: 10.1039/c3rp20170h 